\title{
Fatores que Influenciam o Desempenho Escolar no Estado do Rio Grande do Sul: uma Análise com Regressões Quantllicas*
}

\section{Factors Affecting Performance School at Rio Grande do Sul State: a Quantile Regression Estimation}

\author{
Laura Desirée Silva Vernier** \\ Izete Pengo Bagolin*** \\ Paulo de Andrade Jacinto****
}

\begin{abstract}
Resumo: Nas últimas décadas, a educação vem sendo destacada pela literatura econômica como um importante meio para o crescimento e desenvolvimento econômico. O presente trabalho busca identificar os fatores que influenciaram o desempenho escolar no Rio Grande do Sul no ano de 2007, através de estimações por regressões quantílicas. Para isso, são utilizadas duas formas de análise: uma considerando as proficiências médias das escolas e outra mais desagregada, considerando a proficiência individual dos estudantes e a heterogeneidade das regiões do estado. Na primeira análise, verifica-se que as características dos professores, diretores e alunos são os principais fatores que influenciam no desempenho médio das escolas.Com relação ao resultado para as proficiências individuais, as questões socioeconômicas dos estudantes apresentam efeito significativo. Verificam-se diferenças importantes no desempenho escolar conforme a região, sugerindo que participar de determinado conselho regional de desenvolvimento impacta nas proficiências individuais.
\end{abstract}

Palavras-chave: Função de produção escolar. Proficiência. Desempenho regional.

Abstract: In the past few decades, education has been highlighted by the economic literature as an important mean for growth and economic development. The present study aims to identify the determinants for school achievements at Rio Grande do Sul state for the year 2007 through quantile regression estimation. To that end, two different analysis are made, one considering average grades; and another more desegregated, considering individual students proficiency and intra-state regional heterogeneity. The first analysis showed that teachers, students and school director's characteristics are the prime determinant for average school performance. In regard to individual achievements, socio-economic matters revealed significant effect. Furthermore,

* Trabalho financiado pela Capes no âmbito do Observatório da Educação.

* $\quad$ Doutoranda em Economia do Desenvolvimento pela Faculdade de Administração, Contabilidade e Economia da Pontifícia Universidade Católica do Rio Grande do Sul (PUC-RS). E-mail: lauravernier@gmail.com

*** Doutora em Economia. Professora da Faculdade de Administração, Contabilidade e Economia e do Programa de Pós-Graduação em Economia do Desenvolvimento da PUC-RS. E-mail: izete. bagolin@pucrs.br

**** Doutor em Economia. Professor da Faculdade de Administração, Contabilidade e Economia e do Programa de Pós-Graduação em Economia do Desenvolvimento da PUC-RS. E-mail: paulo. jacinto@pucrs.br 
significant regional differences on school performance were observed, indicating that to participate in a particular Council of Regional Development impacts individual proficiency.

Keywords: Human capital. educational supply. Intergenerational educational mobility.

JEL Classification: I21; I28; P36.

\section{Introdução}

Cada vez mais os países em desenvolvimento buscam melhorar os seus sistemas educacionais. É um interesse que não se restringe apenas a países em desenvolvimento, considerando-se o alto retorno que a educação proporciona aos indivíduos e à sociedade como um todo.

Estudos recentes sobre os determinantes do desempenho nas escolas públicas indicam que o desempenho escolar no Brasil é muito baixo quando comparado aos de outros países. Segundo Menezes-Filho (2007), o aprendizado no país tem seguido uma tendência declinante. No exame internacional Pisa realizado no ano de 2012, mais de 60\% dos estudantes brasileiros não atingiram o nível de proficiência que a Organização para a Cooperação e Desenvolvimento Econômico (OCDE) estabelece como necessário para o pleno exercício da cidadania. Entre as razões para esse baixo desempenho está o atraso escolar dos alunos, seja em função de repetência, seja pela entrada tardia nas escolas. Trata-se de uma situação em que os alunos ainda não teriam aprendido o conteúdo exigido pelo exame para sua determinada idade.

Aparentemente, um baixo desempenho escolar não ocorre apenas no Brasil. Ao analisar o exame que a Unesco realiza com estudantes que cursam a terceira e a quarta séries do ensino fundamental, Menezes-Filho (2007) verifica que o país não está tão mal quando comparado com os demais países da América Latina.

Estudos sobre esse tema têm grande importância na medida em que permitem a elaboração e a implementação de políticas públicas a partir da identificação dos seus principais fatores e o impacto destes sobre o desempenho (proficiência) dos alunos. É por isso que têm surgido inúmeros estudos que fazem uso de diferentes bases de dados, sofisticados métodos econométricos e níveis diferenciados de agregação.

Na literatura nacional sobre o tema, essa questão já vem sendo explorada. O impacto das características dos alunos, da família, dos professores, da escola e do município já foi avaliado em estudos prévios que apresentam recortes temporais, espaciais e metodológicos distintos do presente estudo. Os estudos de Biondi et al. (2009a) e Biondi et al. (2009b) avaliam o impacto de programas específicos ${ }^{1}$

1 Olimpíada Brasileira de Matemática das Escolas Públicas (OBMEP) e Programa Escrevendo o Futuro. 
no desempenho dos alunos na Prova Brasil. É importante destacar que os programas foram desenhados especificamente para incentivar as escolas públicas a melhorarem a educação dos seus alunos. Os resultados dos estudos mostram que esses programas efetivamente têm impacto sobre a proficiência dos alunos. Assim, pode-se inferir que recursos bem empregados na melhora da qualidade educacional levam a futuros benefícios a nível privado e social. Menezes-Filho (2007), Machado et al. (2008) e Felício e Fernandes (2005) destacam em suas avaliações a importância das características dos alunos e da família.

Os estudos de Silva e Hasenbalg (2001) e Curi e Menezes-Filho (2006) destacam o background familiar como principal determinante. No entanto, Machado et al. (2008) e Menezes-Filho (2007) enfatizam que os resultados encontrados não minimizam o papel das políticas públicas para a melhoria da educação. Machado et al. (2008) argumentam que há correlação positiva entre background familiar e qualidade das escolas e que investir nas escolas reduz o efeito família, ampliando o papel da escola. Isso vai ao encontro da sugestão de Menezes-Filho (2007), que considera uma boa política o aumento do número de horas-aula.

Um estudo avaliando a relação entre os insumos escolares e o desempenho dos alunos, realizado por Biondi e Felício (2007), mostra resultados significativos e positivos para a baixa rotatividade de professores, experiência média de mais de dois anos do corpo docente, internet e escolha de diretor que não seja através de concurso, seleção ou indicação. Para o laboratório de informática, os resultados foram significativos, porém o efeito foi negativo.

Sátyro e Soares (2008) e Hanushek et al. (1996) mostram que outros aspectos são importantes e devem ser analisados, como biblioteca, laboratórios e infraestrutura escolar. Soares (2003) analisa a importância das características dos professores e do ambiente em sala de aula. Em 2005, Soares buscou capturar o efeito de três níveis hierárquicos - alunos, turmas e escolas -,porém os resultados mostraram que o efeito da inclusão das características da escola foi baixo em relação à introdução de características dos alunos e das turmas (professores).

Em sua maioria, esses estudos empregam o uso de diferentes bases de dados, como a Prova Brasil, o censo escolar, entre outras, e metodologias de efeitos fixos, como o de mínimos quadrados ordinários (MQO) agrupados, e os modelos hierárquicos, porém nenhum estudo nessa área utilizou o estimador de regressão quantílica (RQ) para explicar a heterogeneidade das proficiências das escolas estudadas. O uso deste método pode ser visto como uma importante ferramenta na análise do desempenho escolar, já que permite uma análise ao longo da distribuição de notas dos alunos (ou escolas), possibilitando avaliar se as características (socioeconômicas, de infraestrutura, diretor e professores) são diferentes entre os alunos (ou escolas) que obtiveram notas baixas e os com elevadas notas. 
Com base nessas considerações, o presente trabalho tem por objetivo identificar os fatores que influenciam o desempenho escolar (médio e individual) no estado do Rio Grande do Sul utilizando o método de RQ e informações do Sistema de Avaliação do Rendimento Escolar do Rio Grande do Sul (Saers). O Saers é uma base de dados específica para o estado e que tem sido pouco explorada nos estudos sobre desempenho escolar. Nesse sentido, o presente estudo procura contribuir com a literatura sobre o tema com o uso de uma base de dados pouco explorada e o uso de um método que permite uma análise ao longo de toda distribuição de notas. Além disso, com a utilização dessa metodologia, o estudo permite verificar se os fatores que influenciam o desempenho dos estudantes apresentam diferenças significativas conforme as regiões do estado.

Este trabalho é composto por mais três seções, além desta breve introdução. Na segunda seção são apresentados o método de estimação, a fonte de dados utilizada e uma descrição sucinta da amostra. Na terceira seção encontram-se os resultados de duas análises diferenciadas, uma com foco na proficiência média da escola, e outra na proficiência individual. Por fim, na quarta seção são apresentadas as considerações finais do trabalho.

\section{Referencial Analítico}

A questão educacional não se baseia somente na quantidade de anos de estudo de um indivíduo, mas principalmente na qualidade dos anos de escolaridade existentes. Há diversas maneiras de se avaliar os determinantes do desempenho escolar. A forma mais geral é através de uma função de produção educacional, apresentada inicialmente por Coleman (1966), na qual busca explicar o desempenho escolar a partir de aspectos pessoais e socioeconômicos dos alunos e de insumos escolares:

$$
\mathrm{Y}=\mathrm{F}(\mathrm{A}, \mathrm{P}, \mathrm{D}, \mathrm{E}, \mathrm{e})
$$

em que $Y$ é o desempenho dos alunos medido pela proficiência, $A$ é um vetor de características dos alunos, como cor, gênero e idade, $P$ é o vetor de características dos professores, D é o vetor de características do diretor, E possui informações sobrea infraestrutura da escola e e é o termo de erro aleatório.

A análise do desempenho escolar neste estudo é feita a partir do uso do estimador de regressões quantílicas e da base de dados do Saers. A seguir, é feita uma descrição do método e da base de dados. 


\subsection{Regressão Quantlilica}

A análise dos determinantes do desempenho escolar é aplicada a partir da metodologia introduzida por Koenker e Basset (1978). Tal metodologia é conhecida como o método de RQ. Esse método foi precedido pelo método dos MQO, que estima a resposta média da variável dependente em termos dos valores das covariáveis. Visto que o MQO é baseado no valor médio, assume-se que há simetria na distribuição da variável dependente com relação às covariáveis, concedendo uma visualização incompleta da sua distribuição.

Apesar das vantagens apresentadas pelo $\mathrm{MQO}$, o método de RQ se sobrepõe em alguns pontos. A estimação pelo método de $R Q$ possibilita identificar variações inter e intraquartis, não comportado pelo $\mathrm{MQO}$, uma vez que é baseado na média da distribuição condicional. Assim, com a utilização de RQ, torna-se viável obter um estimador robusto para cada quartil condicional. Com relação ao número de quartis utilizados, como não há uma única especificação, esta pode variar conforme a pesquisa.

Além de permitir caracterizar toda a distribuição condicional, verificam-se outras vantagens na utilização de RQ. Trata-se de um método robusto a outliers que permite estimar os intervalos de confiança dos parâmetros e do regressando diretamente dos quartis condicionais, e, além disso, o fato de os erros não possuírem distribuição normal permite que os estimadores sejam mais eficientes.

A metodologia aplicada neste estudo se deve ao fato de as escolas serem pouco homogêneas, o que poderia implicar em problemas como de heterocedasticidade e de presença de outliers. Esses problemas poderiam gerar outros, afetando a eficiência e a consistência dos estimadores por MQO. Dessa forma, optando-se pela estimação por RQ, pode-se superar os possíveis problemas apresentados na estimação de $\mathrm{MQO}$ e tornar os resultados mais robustos.

O modelo estimado neste estudo segue um modelo de regressão linear, com dados cross-section semelhantes a:

$$
\mathrm{y}_{\mathrm{i}}=\mathrm{x}_{\mathrm{i}}^{\prime} \beta_{\tau}+\mathrm{u}_{\tau, \mathrm{i}} \text {, para } i=1, \ldots, v \text { e } \tau[0,1]
$$

em que $\mathrm{y}_{\mathrm{i}}$ é a variável dependente, $\mathrm{x}_{\mathrm{i}}$ é uma matriz $n x k$ de variáveis explicativas, $\beta$ é o vetor $k \times 1$ de parâmetros a serem estimados, $u$ é o erro e $\tau$ é denominado $\tau$-ésimo quartil de $y$, para $0<\tau<1$, sendo $\tau=1 / 2$ o quartil referente à mediana. 
Os parâmetros estimados por esse método são obtidos pelo problema de minimização, devendo-se encontrar o $y$ que minimize o erro esperado. Assim, a função objetivo assume a seguinte forma:

$$
\min _{\beta \in \Re} n^{-1}\left[\sum_{i: y_{i} \geq x_{i}^{\prime} \beta} \tau\left|y_{i}-x_{i}^{\prime} \beta_{\tau}\right|+\sum_{i: y_{i} \geq x_{i}^{\prime} \beta}(1-\tau)\left|y_{i}-x_{i}^{\prime} \beta_{\tau}\right|\right]
$$

Essa equação também pode ser expressa como:

$$
\min _{\beta \in \Re} n^{-1} \sum_{i=1}^{n} \rho_{\tau}\left(y_{i}-x_{i}^{\prime} \beta_{\tau}\right)
$$

sendo que $\rho_{\tau}$ é uma função check em que os resíduos são multiplicados por (1- $\tau$ ) se forem negativos e por $\tau$ se forem nãonegativos. A função é definida por:

$$
\rho_{\tau}=\left\{\begin{array}{c}
\tau u, u \geq 0 \\
(1-\tau) u, u<0
\end{array}\right.
$$

Na seção seguinte é apresentada a fonte dos dados utilizada no presente trabalho.

\subsection{Dados}

Para se alcançar os objetivos propostos, são utilizados os microdados do Saers $^{2}$ referentes ao ano de 2007. Esse sistema é coordenado pela Secretaria da Educação do Rio Grande do Sul. Sua base consiste em questionários e contém informações sobre alunos, professores, diretores e infraestrutura de escolas públicas e privadas em todo o estado do Rio Grande do Sul.

As escolas participantes são as da rede pública estadual, urbanas e rurais, independentemente do número de alunos, além de escolas municipais e particulares cujas mantenedoras aderirem ao Saers. O teste diagnostica as habilidades cognitivas desenvolvidas pelos alunos da segunda série (terceiro ano) e da quinta série (sexto ano) do ensino fundamental e do primeiro ano do ensino médio nas áreas de língua portuguesa e matemática. Este trabalho tem como foco a disciplina de matemática para a quinta série do ensino fundamental.

2 O Saers é uma iniciativa da Secretaria da Educação, em parceria com a União Nacional dos Dirigentes Municipais de Educação (Undime/RS) e com o Sindicato dos Estabelecimentos do Ensino Privado do Rio Grande do Sul (Sinepe/RS). O sistema visa avaliar, de forma objetiva e sistemática, a qualidade da educação básica oferecida nas escolas gaúchas (SAERS, 2007). 
Além dos testes, o Saers aplica questionários a alunos, professores e diretores com o objetivo de identificar fatores externos e internos às escolas que influenciam os resultados de aprendizagem dos alunos.

Na próxima seção são apresentadas as variáveis e as estatísticas descritivas.

\subsection{Variáveis Utilizadas e Estatísticas Descritivas}

A amostra final a ser utilizada no estudo foi gerada a partir de filtros que resultaram na exclusão de alunos e escolas sem código identificador. A partir disso, verificou-se um redimensionamento no número de escolas, de 5.273 para 2.930.

\subsubsection{Variáveis Utilizadas}

Na primeira parte deste estudo, a variável dependente é o logaritmo natural da proficiência média por escola; e na segunda, o logaritmo natural da proficiência por aluno. O Quadro 1descreve as variáveis estudadas. ${ }^{3}$

Quadro 1 - Nome, descrição e formato das variáveis

\begin{tabular}{|c|c|}
\hline Variáveis & Descrição \\
\hline \multicolumn{2}{|l|}{ Dependente } \\
\hline In_med_escola & $\begin{array}{l}\text { Logaritmo natural da proficiência média em matemática - } \\
\text { quinta série do EF }\end{array}$ \\
\hline In_aluno & $\begin{array}{l}\text { Logaritmo natural da proficiência individual em matemática } \\
\text { - quinta série do } E F\end{array}$ \\
\hline \multicolumn{2}{|l|}{ Alunos } \\
\hline Sexo & O aluno é do sexo masculino ( $1=\operatorname{sim} / 0=$ não $)$ \\
\hline Bolsa & A família do aluno recebe Bolsa Família ( $1=\operatorname{sim} / 0=$ não) \\
\hline Banheiro & O aluno não tem banheiro em casa $(1=\operatorname{sim} / 0=$ não $)$ \\
\hline Geladeira & $\mathrm{O}$ aluno tem uma geladeira em casa $(1=\operatorname{sim} / 0=$ não $)$ \\
\hline Dever & O aluno faz o dever de casa $(1=\operatorname{sim} / 0=$ não $)$ \\
\hline Livros & O aluno possui mais de 20 livros em casa $(1=\operatorname{sim} / 0=$ não $)$ \\
\hline Automóvel & A família do aluno possui automóvel $(1=\operatorname{sim} / 0=$ não $)$ \\
\hline \multicolumn{2}{|l|}{ Diretor } \\
\hline D_Sexo & O diretor é do sexo masculino $(1=\operatorname{sim} / 0=$ não $)$ \\
\hline D_Traed & Tempo de trabalho do diretor com educação \\
\hline Proposta & O diretor elaborou proposta pedagógica ( $1=\operatorname{sim} / 0=$ não) \\
\hline
\end{tabular}

3 As variáveis utilizadas seguem a literatura da área e a disponibilidade na base de dados. 
conclusão.

\begin{tabular}{|c|c|}
\hline Variáveis & Descrição \\
\hline $\operatorname{Red} A b$ & $\begin{array}{l}\text { Há na escola programa de redução das taxas de abandono } \\
(1=\operatorname{sim} / 0=\text { não })\end{array}$ \\
\hline Red_Rep & $\begin{array}{l}\text { Há na escola programa de redução das taxas de reprovação } \\
(1=\operatorname{sim} / 0=\text { não })\end{array}$ \\
\hline Rec_Pa & $\begin{array}{l}\text { Há na escola processo de recuperação paralela }(1=\operatorname{sim} / \\
0=\text { não) }\end{array}$ \\
\hline D_Superior & O diretor possui ensino superior $(1=\operatorname{sim} / 0=$ não $)$ \\
\hline D_Posgrad & O diretor possui pós-graduação ( 1 =sim / $0=$ não $)$ \\
\hline Aval & Há na escola avaliação dos professores $(1=\operatorname{sim} / 0=$ não $)$ \\
\hline \multicolumn{2}{|l|}{ Professor } \\
\hline P_Sexo & \% de professores do sexo masculino por escola \\
\hline P_Pedag & $\begin{array}{l}\text { \% de professores com Curso Superior em Pedagogia por } \\
\text { escola }\end{array}$ \\
\hline P_Supnor & \% de professores com Ensino Superior normal por escola \\
\hline P_Licen & $\%$ de professores com licenciatura por escola \\
\hline P_Supout & $\begin{array}{l}\text { \% de professores com outros superior/outros na 5EF por } \\
\text { escola }\end{array}$ \\
\hline P_Espec & $\%$ de professores com especialização (min. 360h) por escola \\
\hline P_Mestrad & $\%$ de professores com mestrado por escola \\
\hline P_Nenh & $\%$ de professores com nenhum título por escola \\
\hline P_estatutario & $\%$ de professores com regime estatutário por escola \\
\hline p_clt & \% de professores com regime celetista por escola \\
\hline \multicolumn{2}{|l|}{ Escola } \\
\hline Rede & $\begin{array}{l}\text { Esfera administrativa ( } 1=\text { Estadual; } 2=\text { Municipal; } 3=\text { Particu- } \\
\text { lar) }\end{array}$ \\
\hline Resbil & Há algum responsável pela biblioteca ( $1=$ Sim e $0=$ Não) \\
\hline Cesa & Controle de entrada e saída de alunos ( 1 =Sim e $0=$ Não) \\
\hline Cina & $\begin{array}{l}\text { Há quantidade de computadores disponíveis para uso dos } \\
\text { alunos }\end{array}$ \\
\hline Cipr & $\begin{array}{l}\text { Há computadores com internet para os professores }(1=\operatorname{sim} \\
/ 0=\text { não })\end{array}$ \\
\hline Lcie & Há laboratório de ciências $(1=\operatorname{sim} / 0=$ não $)$ \\
\hline Qpol & Háquadra poliesportiva $(1=\operatorname{sim} / 0=$ não $)$ \\
\hline
\end{tabular}

Fonte: Elaboração própria. 
É válido ressaltar que foram feitas algumas adaptações, como as variáveis dir_sup e dir_posg, a fim de se obter variáveis binárias. Assim, dir_sup assume valor igual a zero se o diretor tiver somente ensino médio; e valor igual a um, caso ele tenha curso superior, seja em pedagogia, licenciatura ou outros tipos de ensino superior. O mesmo ocorre para dir posg, em que a variável será igual a um se o diretor possuir título de pós-graduação e igual a zero caso contrário.

\subsubsection{Estatísticas Descritivas}

Os resultados evidenciam um diferencial no desempenho dos alunos conforme a esfera administrativa. Alunos da rede particular obtêm melhores resultados que os da rede pública. Dentro das escolas públicas, verifica-se também essa diferença nas notas, sendo que os estudantes das escolas municipais apresentam melhor desempenho que os das escolas estaduais (ver Gráfico 1).

Gráfico 1 - Proficiência por esfera administrativa

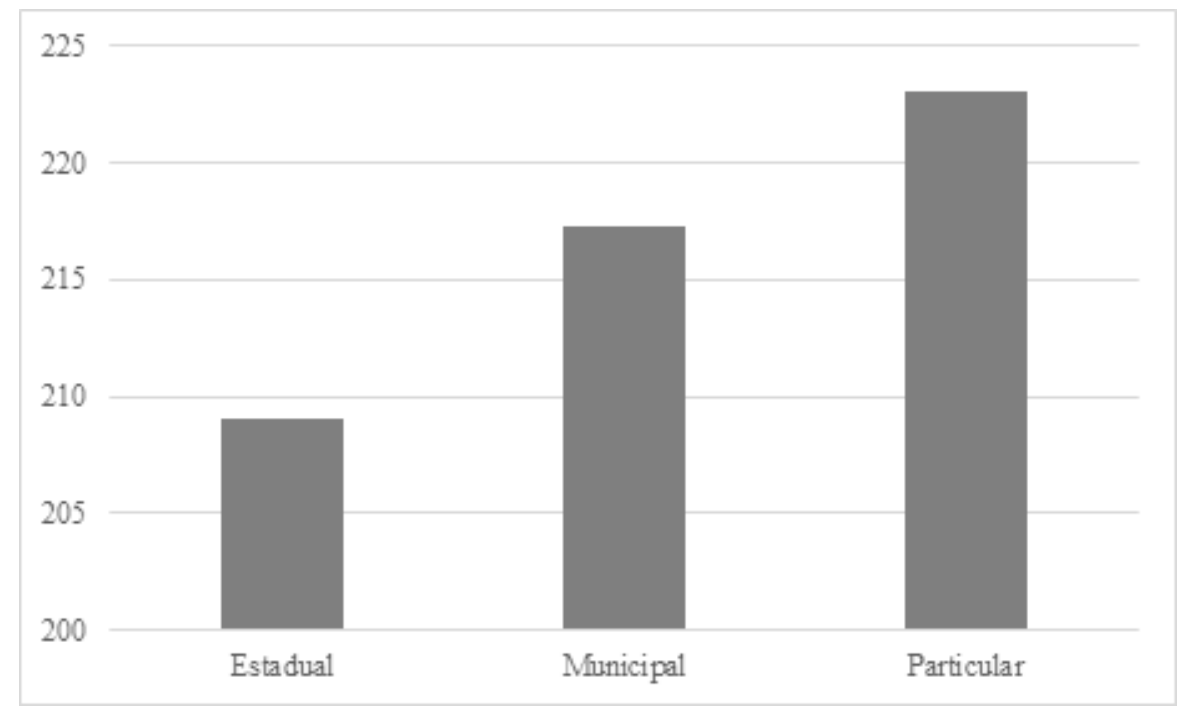

Fonte: Elaboração própria a partir de dados do Sistema de Avaliação do Rendimento Escolar do Rio Grande do Sul (2007).

Quando comparada a proficiência por sexo, verifica-se que não há grande diferença nas notas de matemática na quinta série do ensino fundamental. Ao se analisar a amostra como um todo, em séries mais avançadas, como o primeiro ano do ensino médio, a diferença é maior: nessa série, alunos do sexo masculino obtêm melhores resultados (ver Gráfico 2). 


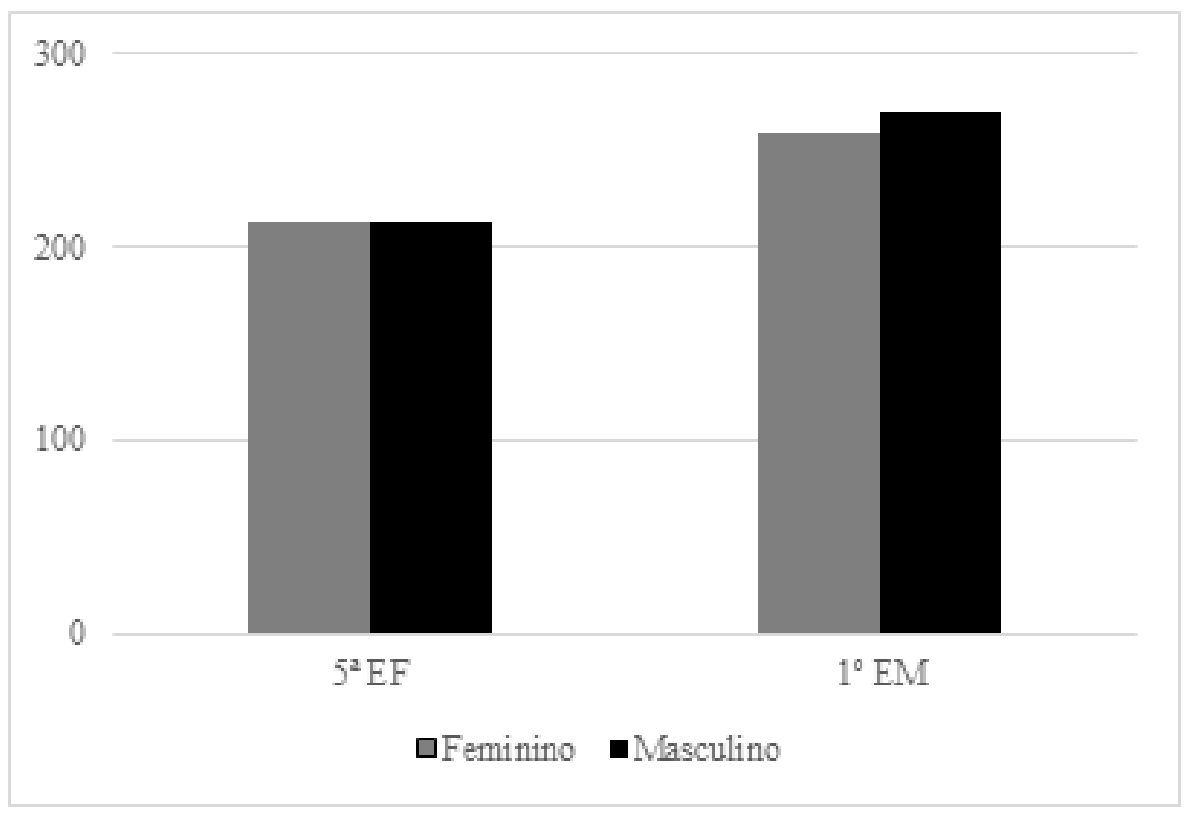

Fonte: Elaboração própria a partir de dados do Sistema de Avaliação do Rendimento Escolar do Rio Grande do Sul (2007).

Com relação ao corpo docente, observa-se que $96,57 \%$ dos professores de matemática possuem nível superior e 77,83\% da amostra possuem curso de licenciatura. Professores com pós-graduação representam 59\% da amostra, sendo que $48,23 \%$ são referentes à especialização. Analisando o sexo dos professores, verifica-se que somente 10,07\% são do sexo masculino (ver Tabela 1).

Tabela 1 - Características dos professores e diretores (\%)

\begin{tabular}{lcc}
\hline & Diretor & Professor \\
\hline Masculino & $15,50 \%$ & $10,07 \%$ \\
Ensino superior & $\mathbf{9 4 , 7 8 \%}$ & $\mathbf{9 6 , 5 7 \%}$ \\
Licenciatura & $50,12 \%$ & $77,83 \%$ \\
Ensino superior normal & $1,19 \%$ & $1,17 \%$ \\
Pós-graduação & $\mathbf{7 4 , 6 7 \%}$ & $\mathbf{5 9 \%}$ \\
Especialização & $65,30 \%$ & $48,23 \%$ \\
Mestrado & $1,30 \%$ & $1,58 \%$ \\
\hline
\end{tabular}

Fonte: Elaboração própria a partir de dados do Sistema de Avaliação do Rendimento Escolar do Rio Grande do Sul (2007). 
Assim como os professores, em sua maioria os diretores apresentam nível superior, principalmente com o título de licenciatura. A proporção de diretores com ensino superior é de 94,78\% e, com pós-graduação, de 74,67\%. Com relação às características pessoais dos diretores, somente 15,5\% dos diretores são do sexo masculino e $69,62 \%$ dos diretores apresentam entre 40 e 54 anos de idade.

\section{Análise dos Resultados}

Os resultados obtidos nas estimações da função de produção escolar são descritos em duas subseções. Na primeira, são apresentados os resultados para a proficiência média da escola, e, na segunda, para a proficiência individual do estudante. A vantagem da $R Q$ reside em se obter coeficientes para os quartis $(0,10$; 0,$25 ; 0,50 ; 0,75$ e 0,90 ), permitindo realizar comparações entre os coeficientes estimados ao longo da distribuição condicional da proficiência. Na análise, a estratégia adotada é a de comparações entre os coeficientes estimados do primeiro quartil em relação ao último $(0,90)$, com vista a verificar se há diferença entre os coeficientes.

\subsection{Determinantes do Desempenho Escolar: Proficiência Média da Escola}

A análise realizada nesta seção parte da estimação de uma função de produção escolar usando o estimador de RQ para uma equação que visa identificar o efeito de diversas características no desempenho escolar médio:

$$
\text { Inprofmed }{ }_{\mathrm{i}}=\beta_{0 \tau}+\beta_{1 \tau} \mathrm{A}_{\mathrm{i}}+\beta_{2 \tau} \mathrm{P}_{\mathrm{i}}+\beta_{3 \tau} \mathrm{D}_{\mathrm{i}}+\beta_{4 \tau} \mathrm{E}_{\mathrm{i}}+\mu_{\tau}
$$

em que profmed é o logaritmo da nota média da escola $i$. A nota avaliada será a resultante dos testes de matemática do Saers em 2007. $\beta_{0 \tau}$ é uma constante, $A_{i}$ é um vetor que contém as características dos alunos da escola $i, P_{i}$ contém as variáveis referentes aos professores de matemáticada escola $i$, Di contém as informações sobre os diretores da escola i e $E_{i}$ éas características de infraestrutura da escola $i$. A partir da estimação da equação, pode-se obter os vetores dos coeficientes em cada quartil, os quais nos indicarão o impacto marginal no $\tau$-ésimo quartil condicional devido a uma mudança no i-ésimo elemento de $x$, isto é, uma mudança nas características de alunos, professores, diretores e infraestrutura.

Inicialmente, em um modelo estimado somente com as características dos alunos, foram identificadas diversas variáveis significativas e que, porém, perderam sua significância estatística com a inclusão das características do diretor. Entre estas temos variáveis de cor e idade. Alunos considerados brancos apresentavam efeito positivo e significativo em todos os quartis, exceto nas escolas pertencentes 
ao quartil de menores proficiências médias. Isso pode estar ocorrendo porque, nas escolas de menores proficiências, as dificuldades são mais homogêneas e podem se sobrepor às características individuais dos estudantes.

Incluindo as demais características, da escola, do diretor e dos professores, somente uma variável relacionada ao questionário do aluno permaneceu significativa. A variável referente ao sexo do aluno foi negativa, indicando que alunos do sexo masculino tendem a obter pior desempenho que os do sexo feminino. No estudo de Franco (2008), que tem como foco a disciplina de matemática para a quarta série, a variável relacionada aos alunos do sexo masculino também apresentou sinal negativo.

Analisando o grupo das escolas com as proficiências 10\% mais baixas, além do gênero do aluno, identifica-se relevância no gênero do diretor. Os resultados indicam que escolas com diretores do sexo masculino tendem a impactar positivamente nas proficiências das escolas com baixo desempenho. Ainda considerando as questões relacionadas ao diretor, verifica-se que a criação de programas com foco nos alunos em grupos de escola de proficiência média baixa também pode influenciar nas notas.

Segundo os resultados apresentados para esse quartil, as características da escola, como segurança e infraestrutura, também apresentam impacto na proficiência. A variável de controle de entrada e saída dos alunos foi positiva, indicando que escolas com esse controle tendem a obter melhor desempenho. Em geral, escolas com baixo desempenho tendem a estar em ambientes hostis e violentos. Com maior segurança, os alunos e professores podem obter maiores estímulos.

No quesito infraestrutura, somente uma variável se mostrou significativa. A existência de laboratório de ciências gera um impacto positivo nas notas médias das escolas com baixa proficiência, a um nível de 11\% de significância.

Com relação às características dos professores nas escolas com menores médias de desempenho, somente uma variável referente à pós-graduação foi significativa. Apesar de significativa, a variável para proporção de professores com especialização, $p_{-}$esp_mt, mostrou-se negativa. Um resultado semelhante é identificado no quartil mais elevado, em quea variável para a proporção de professores com mestrado também apresentou sinal negativo.

Uma especificação alternativa foi testada; nesta, agruparam-se as variáveis referentes à pós-graduação dos professores. Dessa forma, $p \_$posg_mt equivale à soma das proporções de especialização, aperfeiçoamento, mestrado e doutorado. O mesmo resultado encontrado para especialização, no primeiro quartil, e para mestrado, no último quartil, foi verificado em $p \_$posg_ $m t$, significativo e negativo. De acordo com o que defendem Hanushek et al.(2005), a escolaridade/titulação dos professores não capta a qualidade do professor, não refletindo a sua capacidade de agregar maior conhecimento aos alunos. 
Retornando à especificação inicial, no quartil 90, além de se verificar sinal negativo na variável da proporção de professores com mestrado, outra questão foi relevante. Essa questão está relacionada à experiência do diretor com educação. Como explicado nas variáveis descritivas, a variável traed é subdividida em faixas. Os resultados indicam três faixas significativas e positivas: "de 5 a 10 anos", "de 11 a 15 anos" e "mais de 15 anos". Os coeficientes se tornam maiores e mais significativos conforme a faixa de maior tempo. Dessa forma, pode-se inferir que, quanto maior a experiência do diretor com educação, maior é o reflexo no desempenho escolar. Os resultados descritos podem ser observados na Tabela 2.

Tabela 2 - Resultados para a proficiência média da escola

\begin{tabular}{|c|c|c|c|c|c|}
\hline Variável & q10 & q25 & q50 & q75 & q90 \\
\hline \multicolumn{6}{|l|}{ Alunos } \\
\hline \multirow[t]{2}{*}{ Masculino } & $-0.712^{*}$ & $-0.487^{*}$ & -0.0774 & -0.0110 & -0.0407 \\
\hline & $(0.376)$ & $(0.278)$ & $(0.248)$ & $(0.241)$ & $(0.285)$ \\
\hline \multirow[t]{2}{*}{20 livros em casa } & 0.323 & 0.0462 & -0.153 & -0.166 & -0.132 \\
\hline & $(0.340)$ & $(0.259)$ & $(0.206)$ & $(0.230)$ & $(0.259)$ \\
\hline \multirow{2}{*}{ Automóvel } & 0.179 & 0.112 & $0.358 * *$ & 0.0630 & -0.0340 \\
\hline & $(0.277)$ & $(0.237)$ & $(0.172)$ & $(0.161)$ & $(0.182)$ \\
\hline \multicolumn{6}{|l|}{ Diretor } \\
\hline \multirow[t]{2}{*}{ Masculino } & $0.135^{*}$ & 0.0629 & 0.0261 & 0.0192 & 0.0664 \\
\hline & $(0.0735)$ & $(0.0611)$ & $(0.0506)$ & $(0.0596)$ & $(0.0695)$ \\
\hline \multirow[t]{2}{*}{ Nível superior } & -0.101 & 0.0545 & -0.106 & -0.0438 & -0.0637 \\
\hline & $(0.134)$ & $(0.118)$ & $(0.102)$ & $(0.100)$ & (0.113) \\
\hline \multirow[t]{2}{*}{ Pós-graduação } & -0.0503 & -0.0768 & -0.0143 & -0.0111 & 0.0179 \\
\hline & (0.0739) & $(0.0617)$ & $(0.0527)$ & $(0.0452)$ & (0.0477) \\
\hline \multirow{2}{*}{$\begin{array}{l}\text { Trabalha com educação } \\
\text { "5 a } 10 \text { anos" }\end{array}$} & -0.00608 & 0.0820 & $0.287^{*}$ & 0.232 & $0.352^{*}$ \\
\hline & (0.187) & $(0.166)$ & (0.148) & $(0.165)$ & $(0.202)$ \\
\hline \multirow{2}{*}{$\begin{array}{l}\text { Trabalha com educação } \\
\text { "11 a } 15 \text { anos" }\end{array}$} & -0.00720 & -0.0292 & 0.239 & 0.271 & $0.385^{*}$ \\
\hline & $(0.150)$ & (0.144) & $(0.152)$ & $(0.172)$ & $(0.206)$ \\
\hline \multirow{2}{*}{$\begin{array}{l}\text { Trabalha com educação } \\
\text { "mais de } 15 \text { anos" }\end{array}$} & -0.00845 & -0.00930 & 0.214 & 0.260 & $0.436 * *$ \\
\hline & (0.138) & $(0.131)$ & $(0.140)$ & $(0.162)$ & $(0.201)$ \\
\hline \multirow{2}{*}{$\begin{array}{l}\text { Existência de proposta } \\
\text { pedagógica }\end{array}$} & 0.0453 & 0.00531 & 0.0409 & -0.0246 & 0.0131 \\
\hline & $(0.0978)$ & $(0.0928)$ & $(0.0650)$ & $(0.0634)$ & $(0.0624)$ \\
\hline
\end{tabular}


continuação...

\begin{tabular}{|c|c|c|c|c|c|}
\hline Variável & q10 & q25 & q50 & q75 & q90 \\
\hline \multirow{2}{*}{$\begin{array}{l}\text { Existência de avaliação } \\
\text { dos professores }\end{array}$} & 0.193 & 0.0157 & -0.0248 & -0.0452 & -0.0281 \\
\hline & $(0.160)$ & $(0.166)$ & $(0.0960)$ & $(0.0807)$ & $(0.0844)$ \\
\hline \multirow{2}{*}{$\begin{array}{l}\text { Programa redução da } \\
\text { taxa de abandono }\end{array}$} & $0.169 * *$ & 0.0181 & -0.0139 & $-0.0939 *$ & -0.0235 \\
\hline & $(0.0769)$ & $(0.0527)$ & $(0.0437)$ & $(0.0489)$ & $(0.0524)$ \\
\hline \multirow{2}{*}{$\begin{array}{l}\text { Programa redução da } \\
\text { taxa de reprovação }\end{array}$} & -0.115 & -0.0480 & -0.0149 & 0.0279 & 0.0287 \\
\hline & $(0.0731)$ & $(0.0592)$ & $(0.0437)$ & $(0.0431)$ & $(0.0493)$ \\
\hline \multirow{2}{*}{$\begin{array}{l}\text { Programa de recuper- } \\
\text { ação }\end{array}$} & 0.122 & 0.0317 & -0.00444 & 0.0253 & 0.0425 \\
\hline & $(0.114)$ & $(0.0940)$ & $(0.0577)$ & $(0.0549)$ & $(0.0670)$ \\
\hline \multicolumn{6}{|l|}{ Professor } \\
\hline \multirow[t]{2}{*}{ Pedagogia } & 0.218 & 0.249 & 0.0303 & 0.0845 & -0.0856 \\
\hline & $(0.209)$ & $(0.167)$ & $(0.137)$ & $(0.131)$ & $(0.147)$ \\
\hline \multirow[t]{2}{*}{ Superior normal } & -0.104 & -0.171 & -0.0620 & -0.148 & -0.282 \\
\hline & $(0.320)$ & $(0.260)$ & $(0.252)$ & $(0.231)$ & $(0.254)$ \\
\hline \multirow[t]{2}{*}{ Licenciatura } & 0.0878 & 0.151 & 0.00437 & 0.106 & -0.0468 \\
\hline & $(0.178)$ & $(0.140)$ & $(0.107)$ & $(0.103)$ & $(0.126)$ \\
\hline \multirow[t]{2}{*}{ Superior - outros } & 0.0710 & 0.114 & -0.00668 & 0.103 & -0.0672 \\
\hline & $(0.197)$ & $(0.154)$ & $(0.124)$ & $(0.121)$ & $(0.143)$ \\
\hline \multirow[t]{2}{*}{ Especialização } & $-0.202 * *$ & -0.107 & -0.0860 & -0.0683 & -0.118 \\
\hline & $(0.0938)$ & $(0.0795)$ & $(0.0795)$ & $(0.0745)$ & $(0.0799)$ \\
\hline \multirow[t]{2}{*}{ Mestrado } & -0.129 & -0.0673 & -0.163 & -0.177 & $-0.345^{* * *}$ \\
\hline & $(0.146)$ & $(0.130)$ & $(0.118)$ & $(0.111)$ & $(0.120)$ \\
\hline \multirow[t]{2}{*}{ Nenhuma pós-graduação } & -0.0809 & -0.0425 & -0.0317 & -0.0315 & -0.0737 \\
\hline & $(0.0914)$ & $(0.0766)$ & $(0.0792)$ & $(0.0775)$ & $(0.0818)$ \\
\hline \multirow[t]{2}{*}{ Celetista } & 0.100 & 0.170 & 0.0667 & 0.107 & 0.104 \\
\hline & $(0.180)$ & $(0.136)$ & $(0.109)$ & $(0.120)$ & $(0.119)$ \\
\hline \multirow[t]{2}{*}{ Estatutário } & 0.0186 & 0.00269 & 0.0530 & 0.0473 & 0.0819 \\
\hline & $(0.0718)$ & $(0.0539)$ & $(0.0399)$ & $(0.0445)$ & $(0.0529)$ \\
\hline \multirow[t]{2}{*}{ Masculino } & 0.0936 & -0.0419 & -0.0548 & $-0.107^{*}$ & -0.0975 \\
\hline & $(0.0832)$ & $(0.0656)$ & $(0.0626)$ & $(0.0634)$ & $(0.0690)$ \\
\hline \multicolumn{6}{|l|}{ Escola } \\
\hline Rede municipal & 0.0742 & $0.112^{*}$ & 0.0357 & 0.0511 & -0.00908 \\
\hline
\end{tabular}


conclusão.

\begin{tabular}{|c|c|c|c|c|c|}
\hline Variável & q10 & q25 & q50 & q75 & q90 \\
\hline & $(0.0745)$ & $(0.0617)$ & $(0.0453)$ & $(0.0477)$ & $(0.0567)$ \\
\hline \multirow[t]{2}{*}{ Rede particular } & 0.432 & 0.259 & 0.211 & 0.153 & -0.0958 \\
\hline & $(0.275)$ & $(0.196)$ & $(0.174)$ & $(0.195)$ & $(0.202)$ \\
\hline \multirow[t]{2}{*}{ Responsável biblioteca } & -0.116 & -0.0731 & -0.0666 & -0.0423 & -0.0166 \\
\hline & $(0.0746)$ & $(0.0599)$ & $(0.0489)$ & $(0.0437)$ & $(0.0536)$ \\
\hline \multirow{2}{*}{$\begin{array}{l}\text { Controle de entrada e } \\
\text { saída de alunos }\end{array}$} & $0.215^{*}$ & 0.0789 & 0.0892 & -0.00205 & 0.0545 \\
\hline & $(0.121)$ & $(0.0907)$ & $(0.0749)$ & $(0.0773)$ & $(0.0782)$ \\
\hline \multirow{2}{*}{$\begin{array}{l}\text { Computador para alunos } \\
\text { "6 a 10" }\end{array}$} & 0.0272 & 0.0190 & 0.0207 & 0.0681 & 0.0524 \\
\hline & $(0.0786)$ & $(0.0629)$ & $(0.0556)$ & $(0.0594)$ & $(0.0650)$ \\
\hline \multirow{2}{*}{$\begin{array}{l}\text { Computador para alunos } \\
\text { "11 a } 15 \text { " }\end{array}$} & -0.0728 & -0.0491 & -0.0229 & 0.0142 & 0.00476 \\
\hline & $(0.0908)$ & $(0.0716)$ & $(0.0487)$ & $(0.0553)$ & $(0.0736)$ \\
\hline \multirow{2}{*}{$\begin{array}{l}\text { Computador para alunos } \\
\text { " } 16 \text { a } 20 "\end{array}$} & -0.173 & -0.0323 & -0.0189 & 0.00381 & 0.0236 \\
\hline & $(0.128)$ & $(0.0858)$ & $(0.0568)$ & $(0.0771)$ & $(0.0810)$ \\
\hline \multirow{2}{*}{$\begin{array}{l}\text { Computador para alunos } \\
\text { "mais de } 30 "\end{array}$} & 0.170 & 0.132 & 0.0624 & -0.0204 & 0.0409 \\
\hline & $(0.171)$ & $(0.119)$ & $(0.110)$ & $(0.128)$ & $(0.173)$ \\
\hline \multirow{2}{*}{$\begin{array}{l}\text { Computador para profes- } \\
\text { sores }\end{array}$} & 0.00705 & -0.0304 & -0.0148 & -0.0282 & -0.0114 \\
\hline & $(0.0345)$ & $(0.0274)$ & $(0.0223)$ & $(0.0269)$ & $(0.0323)$ \\
\hline \multirow[t]{2}{*}{ Quadra poliesportiva } & -0.0468 & 0.0117 & -0.00872 & 0.00843 & 0.0132 \\
\hline & $(0.0612)$ & $(0.0486)$ & $(0.0378)$ & $(0.0403)$ & $(0.0502)$ \\
\hline \multirow[t]{2}{*}{ Laboratório de ciências } & 0.132 & 0.0128 & 0.00169 & -0.0102 & -0.0319 \\
\hline & $(0.0813)$ & $(0.0470)$ & $(0.0431)$ & $(0.0468)$ & $(0.0506)$ \\
\hline
\end{tabular}

Os valores da constante são: $4.809^{* * *}, 5.301^{* * *}, 5.248^{* * *}, 5.371^{* * *}$ e $5.340^{* * *}$

Fonte: Elaboração própria a partir dos dados da pesquisa.

Nota: a) Graus de significância: *10\%; * $5 \%$; ${ }^{* * *} 1 \%$; b) os valores entre parênteses são os desvios padrões.

Dessa forma, pode-se observar que as escolas com desempenho mais baixo apresentam um número maior de determinantes do desempenho. Nesse grupo, verificam-se determinantes em todos os quesitos, nas características dos alunos, dos diretores, dos professores e da escola. Por outro lado, as escolas com melhores proficiências apresentam poucas variáveis com significância, sendo estas a experiência do diretor e a titulação dos professores. 
Esses resultados diferem dos de outros estudos da área, em que as características dos alunos são os principais determinantes do desempenho. No entanto, isso pode ser explicado pelos diferenciais desta análise.

Além de ter outra abrangência geográfica e uma base de dados ainda não utilizada nessa área, este estudo está baseado na proficiência média das escolas. Assim, é de se esperar que as variáveis de impacto não sejam as mesmas das notas individuais, dando maior ênfase às características dos professores, dos diretores e da escola.

A próxima seção apresenta resultados nos quais a ênfase é dada para a proficiência dos alunos - e não mais a média por escola. Trata-se de uma análise mais desagregada e que permite identificar na esfera do aluno as principais variáveis no seu desempenho escolar. Além disso, a análise busca identificar se existem diferenciais de desempenho em função da localização regional dos alunos. Para isso, são utilizados os Conselhos Regionais de Desenvolvimento (Coredes), que se constituem em subdivisões político-administrativas dentro do estado.

\subsection{Determinantes do Desempenho Escolar por Conselhos Regionais de Desenvolvi- mento: Proficiência Individual}

Nesta análise, busca-se examinar o desempenho escolar, identificando a influência de características do aluno, dos professores, dos diretores e da escola na proficiência de matemática dos estudantes gaúchos. A seção anterior tinha como foco a proficiência média da escola. Dessa forma, torna-se interessante realizar uma análise mais desagregada, buscando-se identificar as variáveis que influenciam a nota dos alunos.

As regiões do estado do Rio Grande do Sul apresentam grande heterogeneidade. Nesse sentido, aproveita-se para analisar se o desempenho dos estudantes apresenta diferenças significativas em seus determinantes nas diferentes regiões do estado. Isto é, se pertencer à determinada região gera algum efeito nas proficiências individuais. Essa análise é realizada através da inclusão de uma variável que identifica os Coredes. ${ }^{4}$

Para isso, será incluída uma dummy para cada Corede. No ano de análise, 2007, havia 26 Coredes. No entanto, o presente estudo tem como base para a organização dos municípios a classificação atual, com 28regiões.

Algumas regiões têm como característica a grande geração de renda e sua concentração desta, contrastando com a maioria das regiões com economia agropecuária. De acordo com a participação dos Coredes no PIB do estado, verifica-se

4 Sancionados em 1994 pela Lei Estadual nº 10.284, os Coredes têm como objetivo promover uma maior e melhor integração entre as regiões gaúchas, visando o desenvolvimento regional, harmônico e sustentável dos municípios. 
que somente três respondem por mais de 50\%, sendo o Metropolitano Delta do Jacuí, o do Vale do Rio dos Sinos e o da Serra.

Ressalta-se que, apesar de os Coredes apresentarem grande participação no PIB, pode ocorrer que haja habitantes empobrecidos na região. Com relação à estrutura produtiva, os três Coredes com maior participação apresentam um PIB advindo, primeiramente, de serviços e, posteriormente, da indústria. A agropecuária representa menos de $1 \%$ do Metropolitano Delta do Jacuí e do Vale do Rio dos Sinos e menos de 5\% do da Serra. Os Coredes com maior participação da agropecuária são, respectivamente: Campos de Cima da Serra, Celeiro, Alto da Serra do Botucaraí e Rio da Várzea. A tabela com a participação dos Coredes no PIB estadual, a estrutura do valor adicionado bruto (VAB) e a participação da população nos Estados e encontra no Anexo A deste trabalho.

Visto que a estimação utiliza dummy para cada Corede, o uso de todas as variáveis introduziria colinearidade perfeita, pois a sua soma será igual a um. Assim, o Corede Alto da Serra do Botucaraí foi escolhido para ser a região de referência (ou grupo base) com a qual as comparações são realizadas. Essa região foi escolhida como base por ser a região com menor participação no PIB estadual e de desenvolvimento ecom pior posição, em 2009, no bloco de educação do Índice de Desenvolvimento Socioeconômico (Idese). ${ }^{5}$ Além disso, o Corede do Alto da Serra do Botucaraí apresentou a maior taxa de analfabetismo no ano de 2010.

Para se identificar o efeito de diversas características no desempenho escolar dos alunos da quinta série, adotou-se a estratégia de se iniciar com um modelo apenas com características de alunos e, a partir disso, inserir outros aspectos relevantes, como características da escola, dos professores, dos diretores e dos Coredes. Para tanto, é utilizado o método de RQ, descrito na terceira seção, para os seguintes modelos:

$$
\begin{aligned}
& \text { Inprofaluno }_{i}=\beta_{0 \tau}+\beta_{1 \tau} A_{i}+\mu_{\tau} \\
& \text { Inprofaluno }_{i}=\beta_{0 \tau}+\beta_{1 \tau} A_{i}+\beta_{2 \tau} P_{i}+\mu_{\tau} \\
& \text { Inprofaluno }_{i}=\beta_{0 \tau}+\beta_{1 \tau} A_{i}+\beta_{2 \tau} P_{i}+\beta_{3 \tau} D_{i}+\mu_{\tau} \\
& \text { Inprofaluno }_{i}=\beta_{0 \tau}+\beta_{1 \tau} A_{i}+\beta_{2 \tau} P_{i}+\beta_{3 \tau} D_{i}+\beta_{4 \tau} E_{i}+\mu_{\tau} \\
& \text { Inprofaluno }_{i}=\beta_{0 \tau}+\beta_{1 \tau} A_{i}+\beta_{2 \tau} P_{i}+\beta_{3 \tau} D_{i}+\beta_{4 \tau} E_{i}+\beta_{5} R_{1}+\beta_{6} R_{2} \ldots+\beta_{32} R_{27}+\mu_{\tau}
\end{aligned}
$$

em que lnprofaluno é o logaritmo da nota do aluno i. A nota avaliada será a resultante dos testes de matemática do Saers para a quinta série no ano de 2007. O $\beta_{0 \tau}$ é uma constante, $A_{\mathrm{i}}$ é um vetor que contém as características do aluno $i, P_{i}$ contém as variáveis referentes aos professores de matemática do aluno $i, D_{i}$ contém as informações sobre os diretores da escola do aluno $i, E_{\mathrm{i}}$ éas características de in-

5 O Idese é um índice sintético, composto por 12 indicadores, os quais são divididos em quatro blocos: educação, saneamento e domicílios, renda e saúde. 
fraestrutura da escola do aluno i e $R_{n}$ é a dummy referente ao Corede que o aluno i pertence. A Tabela 3 apresenta os resultados para os quartis 10 e 90 dos quatro primeiros modelos.

Tabela 3 - Resultados para a proficiência individual

\begin{tabular}{|c|c|c|c|c|c|c|c|c|}
\hline \multirow[t]{2}{*}{ Variável } & \multicolumn{2}{|c|}{ Modelo 1} & \multicolumn{2}{|c|}{ Modelo 2} & \multicolumn{2}{|c|}{ Modelo 3} & \multicolumn{2}{|c|}{ Modelo 4} \\
\hline & $\mathrm{q} 10$ & $\mathrm{q} 90$ & q10 & $\mathrm{q} 90$ & $\mathrm{q} 10$ & $\mathrm{q} 90$ & q10 & $\mathrm{q} 90$ \\
\hline \multirow[t]{2}{*}{ Masculino } & $-0.0148 * * *$ & $0.0257 * * *$ & $-0.0148 * * *$ & $0.0257 * * *$ & $-0.0146 * * *$ & $0.0257 * * *$ & $-0.014 * * *$ & $0.0257 * * *$ \\
\hline & $(0.00288)$ & $(0.00160)$ & $(0.00278)$ & $(0.00165)$ & $(0.00280)$ & $(0.00164)$ & $(0.00308)$ & $(0.00148)$ \\
\hline \multirow[t]{2}{*}{ Bolsa } & $-0.0721 * * *$ & $-0.0439 * * *$ & $-0.0721 * * *$ & $-0.0439 * * *$ & $-0.0719 * * *$ & $-0.0440 * * *$ & $-0.071 * * *$ & $-0.043 * * *$ \\
\hline & $(0.00244)$ & $(0.00162)$ & $(0.00183)$ & $(0.00150)$ & $(0.00211)$ & $(0.00143)$ & $(0.00250)$ & $(0.00132)$ \\
\hline \multirow[t]{2}{*}{ Banheiro } & $-0.0976 * * *$ & $-0.0831 * * *$ & $-0.0977 * * *$ & $-0.0830 * * *$ & $-0.0973^{* * *}$ & $-0.0831 * * *$ & $-0.097 * * *$ & $-0.083^{* * *}$ \\
\hline & $(0.00730)$ & $(0.00380)$ & $(0.00859)$ & $(0.00334)$ & $(0.00740)$ & $(0.00377)$ & $(0.00734)$ & $(0.00370)$ \\
\hline \multirow[t]{2}{*}{ Geladeira } & $0.0992 * * *$ & $0.0342 * * *$ & $0.0993 * * *$ & $0.0341^{* * *}$ & $0.0994^{* * * *}$ & $0.0341^{* * *}$ & $0.0996 * * *$ & $0.0342^{* * * *}$ \\
\hline & $(0.00320)$ & $(0.00194)$ & $(0.00378)$ & $(0.00195)$ & $(0.00354)$ & $(0.00179)$ & $(0.00387)$ & $(0.00194)$ \\
\hline \multirow[t]{2}{*}{ Automóvel } & $0.0250 * * *$ & $0.0193 * * *$ & $0.0249 * * *$ & $0.0194 * * *$ & $0.0252^{* * * *}$ & $0.0193^{* * *}$ & $0.0251 * * *$ & $0.0192^{* * * *}$ \\
\hline & $(0.00294)$ & $(0.00189)$ & $(0.00266)$ & $(0.00166)$ & $(0.00239)$ & $(0.00179)$ & $(0.00239)$ & $(0.00188)$ \\
\hline \multirow[t]{2}{*}{ Dever de casa } & $0.0427 * * *$ & $0.0234^{* * * *}$ & $0.0425 * * *$ & $0.0235^{* * *}$ & $0.0427 * * *$ & $0.0235^{* * *}$ & $0.0425 * * *$ & $0.0234 * * *$ \\
\hline & $(0.00325)$ & $(0.00159)$ & $(0.00330)$ & $(0.00197)$ & $(0.00298)$ & $(0.00163)$ & $(0.00285)$ & $(0.00197)$ \\
\hline \multirow[t]{2}{*}{ Livros } & $-0.0148^{* * *}$ & $0.0437^{* * *}$ & $-0.0148^{* * *}$ & $0.0436 * * *$ & $-0.0148^{* * *}$ & $0.0436^{* * *}$ & $-0.014 * * *$ & $0.043 * * *$ \\
\hline & $(0.00375)$ & $(0.00209)$ & $(0.00423)$ & $(0.00235)$ & $(0.00302)$ & $(0.00222)$ & $(0.00354)$ & $(0.00182)$ \\
\hline Pós-graduação & & & $0.0426^{*}$ & $0.0349 * *$ & $\begin{array}{l}-0.00783 \\
(0.0160)\end{array}$ & 0.0224 & $\begin{array}{l}-0.0198 \\
(0.0231)\end{array}$ & 0.0140 \\
\hline \multirow{2}{*}{ Experiência } & & & & $(0.0171)$ & $0.0609^{* * *}$ & 0.0126 & 0.0362 & -0.00140 \\
\hline & & & & & $(0.0138)$ & $(0.0107)$ & $(0.0303)$ & $(0.0194)$ \\
\hline Recuperação & & & & & & & $\begin{array}{r}-0.00995 \\
(0.0218)\end{array}$ & $\begin{array}{c}0.0197 \\
(0.0172)\end{array}$ \\
\hline \multirow{3}{*}{$\begin{array}{l}\text { Laboratório de } \\
\text { ciências }\end{array}$} & & & & & & & $(0.0210)$ & (0.0172) \\
\hline & & & & & & & 0.0300 & -0.0238 \\
\hline & & & & & & & $(0.0321)$ & $(0.0171)$ \\
\hline \multirow{2}{*}{$\begin{array}{l}\text { Quadra } \\
\text { poliesportiva }\end{array}$} & & & & & & & 0.0102 & 0.0264 \\
\hline & & & & & & & $(0.0236)$ & $(0.0226)$ \\
\hline
\end{tabular}

As constantes são: $5.012^{* * *}, 5.532^{* * *}, 5.012^{* * *}, 5.532^{* * *}, 5.011^{* * *}, 5.532^{* * *}, 5.011^{* * *}$ e $5.532 * * *$ Fonte: Elaboração própria a partir dos dados da pesquisa.

Nota: a) Graus de significância: *10\%; ** $5 \%$; ***1\%; b) os valores entre parênteses são os desvios padrões.

No modelo1, em que são consideradas somente as características dos alunos, identifica-se significância de 1\% em todas as variáveis. Algumas, no entanto, apresentam alteração de sinal conforme o quartil. Isto é, no grupo de alunos com baixo desempenho, verifica-se que ser do sexo masculino impacta negativamente a proficiência de matemática. Por outro lado, no grupo de alunos com maiores notas, o fato de estes serem do sexo masculino gera um efeito positivo nas proficiências. O mesmo ocorre para alunos com mais de 20livros em casa. No entanto, tende a haver um impacto negativo nas notas dos estudantes pertencentes ao quartil de pior desempenho e um impacto positivo nos estudantes com melhores resultados. Isso pode ser um indicativo de que alunos com pior desempenho não respondem aos incentivos tradicionais.

As demais variáveis seguem um padrão, permanecendo com o mesmo sinal em ambos os quartis. Com relação às condições socioeconômicas, observa-se que alunos que não possuem banheiro em casa tendem a obter um pior desempenho em relação aos demais. Além disso, pertencer a uma família com posse de auto- 
móvel, ou que tenha pelo menos uma geladeira em casa, impacta em um melhor desempenho escolar.

O fato de a família do aluno receber Bolsa Família também está relacionado com a renda, uma vez que, para receber esse benefício, a família deve apresentar baixo rendimento familiar. Essa variável apresenta um sinal negativo e significativo, indo ao encontro das demais variáveis desse grupo. Isso é intuitivo, uma vez que alunos oriundos de famílias com baixa renda tendem a apresentar baixo desempenho.

Além das variáveis utilizadas como proxy para renda, a questão da dedicação por parte do aluno tem grande relevância. Os resultados indicam que alunos que fazem os deveres de casa têm melhor desempenho. A magnitude dos coeficientes indica algo interessante, em queo impacto de fazer os deveres é quase duas vezes maior na proficiência dos alunos pertencentes ao grupo de pior desempenho do que no outro grupo.

Adicionando-se a categoria professor, as características dos alunos permanecem significativas a $1 \%$ e apresentam os mesmos sinais do modelo 1 . A variável pós-graduação dos professores é positiva nos dois quartis, indicando que alunos com professores pós-graduados tendem a obter melhores resultados.

No modelo 3, além das características dos alunos e dos professores, são analisadas as características dos diretores. Com a inclusão da variável experiência do diretor com educação, o fato de os professores serem pós-graduados perde a significância. Com relação ao diretor, a experiência apresentou efeito somente no quartil de alunos com menores notas.

Incluindo as questões da escola, as variáveis dos professores e diretores perdem significância. Os resultados indicam que a existência de laboratório de ciências, de quadra poliesportiva e recuperação paralela para os alunos não tem efeito sobre o desempenho dos estudantes. Com relação aos alunos, suas características apresentam os mesmos sinais e nível de significância.

Além dessas características, o modelo 5 analisa se o fato de pertencer à determinada região gera impacto sobre a proficiência dos estudantes gaúchos. Os resultados desse modelo estão descritos na Tabela 4.

Tabela 4 - Resultados para proficiência individual por Coredes (modelo 5)

\begin{tabular}{lccccc}
\hline Variável & \multicolumn{1}{c}{$\mathbf{q 1 0}$} & $\mathbf{q 2 5}$ & $\mathbf{q 5 0}$ & \multicolumn{1}{c}{$\mathbf{q 7 5}$} & $\mathbf{q 9 0}$ \\
\hline Masculino & $-0.0147^{* * *}$ & 0.000805 & $0.0152^{* * *}$ & $0.0249^{* * *}$ & $0.0278^{* * *}$ \\
& $(0.00259)$ & $(0.00157)$ & $(0.00153)$ & $(0.00162)$ & $(0.00182)$ \\
Bolsa & $-0.0682^{* * *}$ & $-0.0603^{* * *}$ & $-0.0540^{* * *}$ & $-0.0475^{* * *}$ & $-0.0411^{* * *}$ \\
& $(0.00247)$ & $(0.00154)$ & $(0.00131)$ & $(0.00131)$ & $(0.00138)$ \\
Banheiro & $-0.0915^{* * *}$ & $-0.0874 * * *$ & $-0.0844^{* * *}$ & $-0.0815^{* * *}$ & $-0.0769 * * *$ \\
\hline & & & & & continua...
\end{tabular}


continuação...

\begin{tabular}{|c|c|c|c|c|c|}
\hline Variável & q10 & q25 & q50 & q75 & q90 \\
\hline & $(0.00736)$ & $(0.00465)$ & $(0.00333)$ & $(0.00376)$ & $(0.00448)$ \\
\hline \multirow[t]{2}{*}{ Geladeira } & $0.0984^{* * *}$ & $0.0731 * *$ & $0.0524 * * *$ & $0.0412^{* * *}$ & $0.0334^{* * *}$ \\
\hline & $(0.00322)$ & $(0.00201)$ & $(0.00178)$ & $(0.00180)$ & $(0.00247)$ \\
\hline \multirow[t]{2}{*}{ Automóvel } & $0.0216 * * *$ & $0.0206 * * *$ & $0.0209 * * *$ & $0.0185 * * *$ & $0.0157 * * *$ \\
\hline & (0.00296) & $(0.00180)$ & $(0.00148)$ & $(0.00143)$ & $(0.00159)$ \\
\hline \multirow[t]{2}{*}{ Dever de casa } & $0.0427^{* * *}$ & $0.0304 * * *$ & $0.0214^{* * *}$ & $0.0220 * * *$ & $0.0232^{* * *}$ \\
\hline & $(0.00287)$ & $(0.00166)$ & $(0.00136)$ & $(0.00150)$ & $(0.00168)$ \\
\hline \multirow[t]{2}{*}{ Livros } & $-0.0114 * * *$ & $0.00821 * *$ & $0.0288 * * *$ & $0.0420 * * *$ & $0.0446^{* * *}$ \\
\hline & $(0.00374)$ & $(0.00183)$ & $(0.00191)$ & $(0.00175)$ & $(0.00218)$ \\
\hline \multirow[t]{2}{*}{ Pós-graduação } & 0.00203 & 0.0124 & $0.0281 * *$ & 0.0162 & 0.00982 \\
\hline & $(0.0251)$ & $(0.0213)$ & $(0.0126)$ & $(0.0140)$ & $(0.0188)$ \\
\hline \multirow[t]{2}{*}{ Experiência } & 0.0256 & 0.0134 & -0.00316 & -0.00229 & -0.00832 \\
\hline & $(0.0319)$ & $(0.0160)$ & $(0.0100)$ & $(0.0136)$ & $(0.0171)$ \\
\hline \multirow[t]{2}{*}{ Recuperação } & -0.0327 & 0.0101 & 0.00139 & 0.00505 & 0.0154 \\
\hline & $(0.0214)$ & $(0.0178)$ & $(0.0124)$ & $(0.0146)$ & $(0.0174)$ \\
\hline \multirow{2}{*}{$\begin{array}{l}\text { Laboratório de } \\
\text { ciências }\end{array}$} & 0.0556 & $-5.94 e-05$ & 0.00832 & -0.00840 & -0.0190 \\
\hline & $(0.0392)$ & $(0.0275)$ & $(0.0134)$ & $(0.0143)$ & $(0.0163)$ \\
\hline \multirow[t]{2}{*}{ Quadra poliesportiva } & -0.0124 & 0.00791 & 0.0168 & 0.0116 & 0.0288 \\
\hline & $(0.0244)$ & $(0.0174)$ & $(0.0119)$ & $(0.0147)$ & $(0.0194)$ \\
\hline \multirow[t]{2}{*}{ Alto do Jacuí } & $-0.165 * * *$ & $-0.0693 * * *$ & $-0.0178^{*}$ & 0.00534 & $0.0192 *$ \\
\hline & $(0.0229)$ & $(0.0139)$ & $(0.0104)$ & $(0.0119)$ & $(0.0116)$ \\
\hline \multirow[t]{2}{*}{ Campanha } & -0.0249 & $-0.0181 * *$ & $-0.0215 *$ & $-0.0281 * * *$ & $-0.0241^{* *}$ \\
\hline & $(0.0170)$ & $(0.00876)$ & $(0.00836)$ & $(0.0102)$ & $(0.00973)$ \\
\hline \multirow{2}{*}{$\begin{array}{l}\text { Campos de Cima da } \\
\text { Serra }\end{array}$} & -0.00662 & 0.000210 & 0.00132 & -0.00536 & -0.00876 \\
\hline & $(0.0194)$ & $(0.0105)$ & $(0.0108)$ & $(0.00996)$ & $(0.0111)$ \\
\hline \multirow[t]{2}{*}{ Celeiro } & $-0.0471 * *$ & $-0.0269 * *$ & -0.0110 & -0.00282 & -0.00152 \\
\hline & $(0.0212)$ & $(0.0115)$ & $(0.00958)$ & $(0.0117)$ & $(0.0107)$ \\
\hline \multirow[t]{2}{*}{ Central } & 0.00773 & $0.0146^{*}$ & $0.0176 * *$ & 0.0123 & 0.0103 \\
\hline & $(0.0173)$ & $(0.00876)$ & $(0.00865)$ & $(0.0103)$ & $(0.0103)$ \\
\hline \multirow[t]{2}{*}{ Centro-Sul } & 0.0128 & $0.0204 * *$ & 0.0141 & 0.000526 & -0.00946 \\
\hline & $(0.0185)$ & $(0.00993)$ & $(0.00992)$ & $(0.0109)$ & $(0.0106)$ \\
\hline Fronteira Noroeste & 0.0301 & $0.0517 * * *$ & $0.0587 * * *$ & $0.0589 * * *$ & $0.0470 * * *$ \\
\hline
\end{tabular}


continuação...

\begin{tabular}{|c|c|c|c|c|c|}
\hline Variável & q10 & q25 & q50 & q75 & q90 \\
\hline & $(0.0206)$ & $(0.00952)$ & $(0.00970)$ & $(0.00996)$ & $(0.0116)$ \\
\hline \multirow[t]{2}{*}{ Fronteira Oeste } & -0.0251 & $-0.0164^{* *}$ & $-0.0222 * * *$ & $-0.0287 * * *$ & $-0.0341 * * *$ \\
\hline & $(0.0166)$ & $(0.00771)$ & $(0.00852)$ & $(0.0107)$ & $(0.0102)$ \\
\hline \multirow[t]{2}{*}{ Hortênsias } & 0.0324 & $0.0350 * *$ & $0.0331 * *$ & $0.0331 * *$ & $0.0229 * *$ \\
\hline & $(0.0208)$ & $(0.0106)$ & $(0.0106)$ & $(0.0134)$ & $(0.0102)$ \\
\hline \multirow[t]{2}{*}{ Jacuí Centro } & 0.00665 & $0.0272 * *$ & $0.0179^{*}$ & 0.0132 & 0.00837 \\
\hline & $(0.0180)$ & $(0.0108)$ & $(0.00988)$ & $(0.0122)$ & $(0.0101)$ \\
\hline \multirow[t]{2}{*}{ Litoral } & 0.0119 & $0.0445^{* * *}$ & $0.0341 * * *$ & $0.0306 * * *$ & $0.0249 * *$ \\
\hline & $(0.0213)$ & $(0.0106)$ & $(0.00892)$ & $(0.0106)$ & $(0.0108)$ \\
\hline \multirow[t]{2}{*}{ Médio Alto Uruguai } & -0.00289 & $0.0239 * *$ & $0.0244 * *$ & $0.0219 * *$ & $0.0259 * *$ \\
\hline & $(0.0179)$ & $(0.00993)$ & $(0.0101)$ & $(0.0105)$ & $(0.0105)$ \\
\hline \multirow{2}{*}{$\begin{array}{l}\text { Metropolitano Delta } \\
\text { do Jacuí }\end{array}$} & 0.000984 & $0.0141 *$ & 0.00733 & 0.00100 & -0.00274 \\
\hline & $(0.0161)$ & $(0.00738)$ & $(0.00796)$ & $(0.00975)$ & $(0.00872)$ \\
\hline \multirow[t]{2}{*}{ Missões } & $0.0296^{*}$ & $0.0429 * * *$ & $0.0390 * * *$ & $0.0333 * * *$ & $0.0395 * *$ \\
\hline & $(0.0179)$ & $(0.00938)$ & $(0.00883)$ & $(0.0113)$ & $(0.0107)$ \\
\hline \multirow[t]{2}{*}{ Nordeste } & 0.00589 & $0.0266 * *$ & $0.0269 * * *$ & 0.0139 & 0.0103 \\
\hline & $(0.0190)$ & $(0.0108)$ & $(0.00976)$ & $(0.0126)$ & $(0.0124)$ \\
\hline \multirow[t]{2}{*}{ Noroeste colonial } & 0.0210 & $0.0425 * * *$ & $0.0393 * *$ & $0.0298 * *$ & 0.0131 \\
\hline & $(0.0200)$ & $(0.0110)$ & $(0.00995)$ & $(0.0117)$ & $(0.0103)$ \\
\hline \multirow[t]{2}{*}{ Norte } & 0.0311 & $0.0534 * * *$ & $0.0532 * * *$ & $0.0534 * * *$ & $0.0444 * * *$ \\
\hline & $(0.0195)$ & $(0.00978)$ & $(0.00898)$ & $(0.0112)$ & $(0.0103)$ \\
\hline \multirow{2}{*}{$\begin{array}{l}\text { Paranhana-Encosta } \\
\text { da Serra }\end{array}$} & 0.0280 & $0.0341 * *$ & $0.0268 * * *$ & $0.0206^{*}$ & $0.0202^{*}$ \\
\hline & $(0.0197)$ & $(0.0100)$ & $(0.00933)$ & $(0.0106)$ & $(0.0112)$ \\
\hline \multirow[t]{2}{*}{ Produção } & 0.00823 & $0.0178 * *$ & $0.0223 * *$ & $0.0237^{* *}$ & $0.0253 * *$ \\
\hline & $(0.0171)$ & $(0.00719)$ & (0.00899) & $(0.0102)$ & $(0.0101)$ \\
\hline \multirow[t]{2}{*}{ Rio da Várzea } & 0.00726 & 0.0132 & 0.000929 & -0.00134 & 0.00913 \\
\hline & $(0.0202)$ & $(0.0105)$ & $(0.0103)$ & $(0.0115)$ & $(0.0113)$ \\
\hline \multirow[t]{2}{*}{ Serra } & $0.0643 * * *$ & $0.0677 * * *$ & $0.0587 * * *$ & $0.0460 * * *$ & $0.0439 * * *$ \\
\hline & $(0.0166)$ & $(0.00781)$ & $(0.00807)$ & $(0.00991)$ & (0.00906) \\
\hline \multirow[t]{2}{*}{ Sul } & -0.0125 & 0.00756 & 0.00975 & 0.00868 & 0.00452 \\
\hline & $(0.0179)$ & $(0.00786)$ & $(0.00835)$ & $(0.0101)$ & $(0.00947)$ \\
\hline Vale do Caí & $0.0494 * * *$ & $0.0609 * * *$ & $0.0556 * * *$ & $0.0414 * * *$ & $0.0324 * * *$ \\
\hline
\end{tabular}




\begin{tabular}{lllllc} 
conclusão. & \multicolumn{1}{c}{ q10 } & \multicolumn{1}{c}{ q25 } & \multicolumn{1}{c}{ q50 } & \multicolumn{1}{c}{ q75 } & q90 \\
\hline \multirow{3}{*}{ Vale do Jaguarivel } & $(0.0186)$ & $(0.00860)$ & $(0.00892)$ & $(0.0103)$ & $(0.0111)$ \\
& $-0.0742 * * *$ & $-0.0242 * *$ & -0.0147 & $-0.0214 *$ & -0.00160 \\
Rio dos Sinos & $(0.0232)$ & $(0.0109)$ & $(0.0101)$ & $(0.0115)$ & $(0.0112)$ \\
& $0.0303 *$ & $0.0459 * * *$ & $0.0392 * * *$ & $0.0312 * * *$ & $0.0218 * *$ \\
Vale do Rio do Pardo & $(0.0163)$ & $(0.00752)$ & $(0.00806)$ & $(0.00999)$ & $(0.00873)$ \\
& $(0.0259$ & $0.0422 * * *$ & $0.0401 * * *$ & $0.0370 * * *$ & $0.0319 * * *$ \\
Vale do Taquari & $0.0486 * * *$ & $0.0549 * * *$ & $0.0593 * * *$ & $0.0539 * * *$ & $0.0482 * * *$ \\
& $(0.0171)$ & $(0.00816)$ & $(0.00937)$ & $(0.0111)$ & $(0.0107)$ \\
\hline
\end{tabular}

As constantes da regressão são: $5.002 * * *, 5.143^{* * *}, 5.286^{* * *}, 5.411^{* * *}$ e $5.517 * *$

Fonte: Elaboração própria a partir dos dados da pesquisa.

Nota: a) Graus de significância: *10\%; **5\%; ***1\%; b) os valores entre parênteses são os desvios padrões.

Nesse modelo, a significância das demais características permanece inalterada. Isto é, questões referentes aos alunos permanecem significativas a $1 \%$, enquanto as variáveis nos quesitos professor, diretor e escola não apresentam efeito. Com relação às regiões, observa-se que a maioria dos Coredes tende a influenciar a proficiência de matemática dos alunos de quinta série. Dentre os 26 Coredes estimados, cinco apresentaram significância em todos os quartis. Os Coredes de Missões, Rio dos Sinos, Serra, Vale do Caí e Vale do Taquari apresentaram impacto positivo no desempenho dos estudantes em diversos níveis de proficiência.

São 13 os Coredes que apresentaram significância em três ou quatro quartis. Destes, somente os da Campanha, Fronteira Oeste e Vale do Jaguari mostraram coeficientes negativos. A fim de uma melhor visualização, o Quadro 2 descreve os sinais dos Coredes por número de quartis que se apresentaram significantes.

Quadro 2 - Coredes por número de quartis significantes

\begin{tabular}{|l|c|l|c|l|c|}
\hline \multicolumn{2}{|c|}{ Cinco quartis } & \multicolumn{2}{c|}{ Quatro quartis } & \multicolumn{2}{c|}{ Três quartis } \\
\hline Missões & + & Alto do Jacuí & $-/+$ & Fronteira Noroeste & + \\
\hline Rio dos Sinos & + & Campanha & - & Vale do Jaguari & - \\
\hline Serra & + & $\begin{array}{l}\text { Fronteira } \\
\text { Oeste }\end{array}$ & - & & \\
\hline Vale do Caí & + & Hortênsias & + & & \\
\hline Vale do Taquari & + & Litoral & + & & \\
\hline
\end{tabular}


conclusão.

\begin{tabular}{|l|l|l|c|l|l|}
\hline \multicolumn{2}{|c|}{ Cinco quartis } & \multicolumn{2}{|c|}{ Quatro quartis } & \multicolumn{2}{c|}{ Três quartis } \\
\hline & $\begin{array}{l}\text { Médio Alto } \\
\text { Uruguai }\end{array}$ & + & & \\
\hline & $\begin{array}{l}\text { Noroeste } \\
\text { Colonial }\end{array}$ & + & & \\
\hline & Norte & + & & \\
\hline & $\begin{array}{l}\text { Paranhana- } \\
\text { Encosta da } \\
\text { Serra }\end{array}$ & + & & & \\
\hline & $\begin{array}{l}\text { Produção } \\
\text { Vale do Rio } \\
\text { do Pardo }\end{array}$ & + & + & & \\
\hline
\end{tabular}

Fonte: Elaboração própria.

Os resultados indicam um padrão de sinais conforme os Coredes. No entanto, odo Alto do Jacuí é uma exceção, sendo o único que apresentou sinais diferentes conforme o quartil. No grupo de estudantes com desempenho baixo e mediano, participar desse Corede tem um efeito negativo na proficiência. Por outro lado, se os alunos apresentam bons resultados, o Corede gera um impacto positivo.

Dos 27 Coredes, somente três não foram significantes em nenhum quartil: os de Campos de Cima da Serra, Rio da Várzea e Vale do Caí. Com relação à região metropolitana, participar do Corede Metropolitano Delta Jacuí não foi significante em 80\% dos quartis. Esse apresentou sinal positivo somente no quartil 25.

Analisando os grupos de desempenho, observa-se que os quartis das extremidades apresentaram menos coeficientes significativos que os demais, indicando que os Coredes têm maior influência sobre as proficiências de alunos com desempenho intermediário.

Entre as cinco regiões com maior participação no PIB estadual, estão as dos Coredes Metropolitano Delta do Jacuí, Vale do Rio dos Sinos, Serra, Sul e Vale do Rio do Pardo, respectivamente. Em geral, esses apresentaram uma maior influência no desempenho escolar da região de referência. Somente o Corede Sul não foi significativo. O Corede da região metropolitana apresentou somente um quartil significante, que, por sua vez, vai de acordo com o esperado, mostrando-se positivo.

As regiões com menor participação no PIB, que são as do Vale do Jaguari, Rio da Várzea e Celeiro, apresentaram um impacto negativo na proficiência dos estudantes em matemática. Entre elas, somente o Corede Rio da Várzea não se mostrou significativo. 
Analisando o desenvolvimento regional, os Coredes com maior Ideseno ano de 2009 são, respectivamente, o da Serra e o Metropolitano Delta do Jacuí, coincidindo com os cinco de maior participação no PIB estadual e que se mostraram significativos em pelo menos um quartil.

Os Coredes que, com relação à base, impactaram negativamente são: Campanha, Celeiro, Fronteira Oeste e Vale do Jaguari. O Corede da Campanha, apesar de ter apresentado um Idese geral relativamente alto, ocupando a $10^{\circ}$ posição, representou somente 1,33\% do PIB do Rio Grande do Sul.

O Corede Celeiro apresentou efeito negativo no desempenho escolar somente nos quartis 10 e 25 quando comparado à região base. Essa região apresentou resultados ruins com relação ao Idese geral, taxa de analfabetismo e participação no PIB, ocupando a $4^{\mathrm{a}}$, a $3^{\mathrm{a}}$ e a $25^{\mathrm{a}}$ pior posição respectivamente. No entanto, o bloco da educação não apresentou um resultado tão ruim comparado a essas posições, obtendo o $12^{\circ}$ pior índice.

A região da Fronteira Oeste, apesar de ter indicado um sinal negativo no desempenho, possui um Idese geral maior, menor taxa de analfabetismo e maior participação no PIB do que o Celeiro. No entanto, apesar de essas estatísticas serem melhores, no bloco da educação o Celeiro ocupa melhores posições.

Com relação ao Vale do Jaguari, suas piores referências estão na taxa de analfabetismo e na participação no PIB estadual, ocupando a $10^{\mathrm{a}}$ e a $2^{\mathrm{a}}$ posição, respectivamente.

Diante desses resultados, observa-se que há diferenças significativas no desempenho escolar individual conforme as regiões e que o PIB destas pode ser uma das explicações para isso. Assim, este capítulo revelou a importância das características socioeconômicas dos estudantes e do Corede ao qual pertence na sua proficiência de matemática.

\section{Considerações Finais}

O objetivo deste trabalho é identificar os determinantes do desempenho escolar dos estudantes gaúchos na quinta série do ensino fundamental. Para isso, foram realizados dois estudos por meio do método de estimação por $\mathrm{RQ}$, utilizando informações do Saers para o ano de 2007.

Foi adotada a estratégia de comparar os coeficientes estimados do $1^{\circ}$ quartil com o $9^{\circ}$ quartil com vista a verificar se há diferenças entre os coeficientes, corroborando a hipótese de heterogeneidade das proficiências.

O primeiro estudo buscou identificar o efeito das características dos alunos, dos professores, da escola e dos diretores na proficiência média escolar. Os resultados indicaram que escolas com desempenho mais baixo apresentam um número maior de determinantes do desempenho. Nesse grupo, foram verificados 
determinantes em todos os quesitos, nas características dos alunos, dos diretores, dos professores e da escola. Por outro lado, as escolas com melhores proficiências apresentaram poucas variáveis de impacto, sendo estas a experiência do diretor e a titulação dos professores. Embora questões referentes aos alunos, como status socioeconômico, por exemplo, tenham apresentado significância, não resultaram como o esperado, diferindo dos resultados encontrados na maioria dos estudos da área.

Talvez esses resultados sejam oriundos da perda de heterogeneidade, uma vez que foram feitas média da proficiência escolar. Uma alternativa seria o uso de uma amostra no formato de painel, na qual haveria a possibilidade de acompanhar o desempenho médio ao longo do tempo.

O segundo estudo buscou os determinantes do desempenho de um modo mais desagregado, em que não foram avaliadas as proficiências médias das escolas, mas sim as notas individuais dos estudantes. Foram estimados cinco modelos, nos quais as variáveis, conforme grupos e regiões, foram incluídas gradativamente, e o primeiro modelo continha somente as variáveis referentes aos alunos. As questões socioeconômicas dos alunos apresentaram significância em todos os modelos. Ao se incluir a variável que indica que os professores tenham cursado alguma pós-graduação, verificou-se significância nessa também. No entanto, ocorre perda da significância dessa variável quando, no modelo seguinte, a experiência do diretor com educação entra na análise. Assim, somente as características dos alunos e dos diretores são significativas.

No quarto modelo há a inclusão das características da escola, mas nenhuma variável, com exceção das socioeconômicas, apresentou impacto na proficiência dos estudantes. Ao se considerar as regiões, verificou-se o mesmo resultado já obtido, porém muitas dessas regiões se mostraram significativas, indicando que há diferenciais no desempenho dos estudantes conforme sua participação em determinado Corede.

Assim, de modo mais geral, quando se analisam os determinantes da proficiência média escolar, além das questões socioeconômicas dos estudantes, as características dos professores, dos diretores e da escola também apresentam impacto. Porém, ao se analisar as notas individuais dos alunos, as características perdem o efeito, sendo relevantes somente as variáveis dos alunos. Além disso, os Coredes aos quais os estudantes pertencem também influenciam no desempenho individual. Para futuros trabalhos de análise da proficiência média escolar recomenda-se a utilização de uma metodologia alternativa, como a de dados em painel.

\section{Referências}

BIONDI, R. L. et al. avaliando o impacto da olimpíada brasileira de matemática das escolas públicas no desempenho de matemática nas avaliações educacionais. In: ENCONTRO DA 
SOCIEDADE BRASILEIRA DE ECONOMETRIA, 31., 2009, Foz do Iguaçu. Anais... Foz do Iguaçu: Sociedade Brasileira de Econometria, 2009a.

BIONDI, R. L.; FELÍCIO, F. Atributos escolares e o desempenho dos estudantes: uma análise de painel dos dados do SAEB. Brasília, DF: Inep, 2007.

BIONDI, R. L. et al.Avaliando o impacto do programa escrevendo o futuro no desempenho das escolas públicas na prova Brasil e na renda futura dos estudantes. In: ENCONTRO NACIONAL DE ECONOMIA, 31., 2009, Foz do Iguaçu. Anais... Foz do Iguaçu: Associação Nacional dos Centros de Pós-Graduação em Economia, 2009b.

COLEMAN, J. S. Equality of educational opportunity. Washington: Office Education, 1966.

CURI, A.; MENEZES-FILHO, N. Os efeitos da pré-escola sobre salários, escolaridade e proficiência. São Paulo: IBMEC, 2006.

FELÍCIO, F.; FERNANDES, R. O efeito da qualidade da escola sobre o desempenho escolar: uma avaliação do ensino fundamental no estado de São Paulo. In: ENCONTRO NACIONAL DE ECONOMIA, 33., 2005, São Paulo: Anais... São Paulo: Associação Nacional dos Centros de Pós-Graduação em Economia, 2005.

FRANCO, A. M. P. Os determinantes da qualidade da educação no Brasil. 2008. 146 f. Tese (Doutorado em Economia) - Departamento de Economia, Programa de Pós-Graduação em Economia, Universidade de São Paulo, São Paulo, 2008.

FUNDAÇÃO DE ECONOMIA E ESTATÍSTICA. Dados referentes ao Produto Interno Bruto e Valor Adicionado. Disponível em: <www.fee.tche.br> Acesso em: fevereiro 2015.

HANUSHEK, E. A. A more complete picture of school resource policies. Review of Educational Research, v. 66, n. 2, p. 397-409, 1996.

HANUSHEK, E. A.; KIMKO, D. D. Schooling, labor-force quality and the growth of nations? The American Economic Review, v. 90, n. 5, p. 1184-1208, 2000.

HANUSHEK, E.et al. Teachers, school and academic achievement.Econometrica,v.73, n.2, p. 417-458, 2005.

KOENKER, R.; BASSETT, G. Quantile regression. Econometrica, v.46, n. 1, p.33-50, 1978.

MACHADO, A. F. et al. Qualidade do ensino em matemática: determinantes do desempenho dos alunos em escolas públicas estaduais mineiras. Revista Economia, v. 9, n. 1, p. 23-45, jan./ abr. 2008.

MENEZES-FILHO, N. Os determinantes do desempenho escolar no Brasil. São Paulo: Instituto Futuro Brasil, IBMEC São Paulo, Faculdade de Economia e Administração da Universidade de São Paulo, 2007. (Sumário executivo).

SÁTYRO, N.; SOARES, S. O impacto da infraestrutura escolar na taxa de distorção idade-série das escolas brasileiras de ensino fundamental: 1998 a 2005. Rio de Janeiro: Ipea, maio 2008. (Textos para discussão, n. 1338). 
SILVA, N. V.; HASENBALG, C. Recursos familiares e transições educacionais. Salvador, BA: Associação Brasileira de Estudos Populacionais, jun. 2001. (Versão preliminar apresentada no Workshop de Demografia da Educação).

SISTEMA DE AVALIAÇÃO DO RENDIMENTO ESCOLAR DO RIO GRANDE DO SUL, SAERS. 2007. Disponível em: <http://www.saers.caedufjf.net/saers-inst/home.faces>. Acesso em: 25 jun. 2015.

SOARES, T. M. Influência do professor e do ambiente em sala de aula sobre a proficiência alcançada pelos alunos avaliados no Simave 2002. Estudos em Avaliação Educacional, n. 28, p. 103-124, jul./dez. 2003.

Modelo de três níveis hierárquicos para a proficiência dos alunos de $4^{\mathrm{a}}$ série avaliados no teste de língua portuguesa do SIMAVE/PROEB 2002. Revista Brasileira de Educação, n. 29, p. 73-87, 2005.

Anexo A

Participação no PIB estadual, estrutura do VAB e participação da população no

Estado(2010)

\begin{tabular}{|c|c|c|c|c|c|}
\hline \multirow[b]{2}{*}{ Coredes } & \multirow[b]{2}{*}{$\begin{array}{l}\text { PIB par- } \\
\text { ticipação } \\
\text { (\%) }\end{array}$} & \multicolumn{3}{|c|}{ Estrutura do VAB (\%) } & \multirow[b]{2}{*}{$\begin{array}{l}\text { População } \\
\text { (\%) }\end{array}$} \\
\hline & & $\begin{array}{c}\text { Agro- } \\
\text { pecuária }\end{array}$ & Indústria & Serviços & \\
\hline $\begin{array}{l}\text { Metropoli- } \\
\text { tano do Delta } \\
\text { do Jacuí }\end{array}$ & 26,94 & 0,61 & 28,85 & 70,54 & 22,63 \\
\hline $\begin{array}{l}\text { Vale do Rio } \\
\text { dos Sinos }\end{array}$ & 14,94 & 0,26 & 36,64 & 63,10 & 12,07 \\
\hline Serra & 10,96 & 4,36 & 43,89 & 51,74 & 8,06 \\
\hline Sul & 6,58 & 11,26 & 24,08 & 64,66 & 7,88 \\
\hline $\begin{array}{l}\text { Vale do Rio } \\
\text { Pardo }\end{array}$ & 3,95 & 13,68 & 35,46 & 50,87 & 3,91 \\
\hline $\begin{array}{l}\text { Fronteira } \\
\text { Oeste }\end{array}$ & 3,86 & 24,50 & 18,71 & 56,79 & 4,96 \\
\hline Produção & 3,41 & 11,73 & 20,28 & 67,99 & 3,27 \\
\hline $\begin{array}{l}\text { Vale do Ta- } \\
\text { quari }\end{array}$ & 3,11 & 12,72 & 35,19 & 52,09 & 3,07 \\
\hline Central & 2,59 & 13,42 & 15,39 & 71,20 & 3,66 \\
\hline Norte & 1,93 & 15,34 & 30,94 & 53,72 & 2,07 \\
\hline Missões & 1,83 & 23,88 & 17,66 & 58,46 & 2,32 \\
\hline
\end{tabular}


conclusão.

Estrutura do VAB (\%)

Coredes PIB par- Agro- Indústria Serviços População

ticipação pecuária (\%)

(\%)

\begin{tabular}{|c|c|c|c|c|c|}
\hline $\begin{array}{l}\text { Fronteira } \\
\text { Noroeste }\end{array}$ & 1,72 & 18,38 & 27,36 & 54,26 & 1,90 \\
\hline Alto Jacuí & 1,67 & 16,88 & 18,61 & 64,50 & 1,45 \\
\hline Centro-Sul & 1,64 & 17,88 & 28,84 & 53,28 & 2,37 \\
\hline Litoral & 1,63 & 10,39 & 15,37 & 74,24 & 2,77 \\
\hline $\begin{array}{l}\text { Noroeste } \\
\text { Colonial }\end{array}$ & 1,54 & 15,12 & 18,41 & 66,48 & 1,56 \\
\hline Vale do Caí & 1,50 & 11,98 & 38,48 & 49,55 & 1,59 \\
\hline $\begin{array}{l}\text { Paranhana- } \\
\text { Encosta da } \\
\text { Serra }\end{array}$ & 1,41 & 3,31 & 40,91 & 55,77 & 1,92 \\
\hline Campanha & 1,33 & 19,94 & 20,42 & 59,64 & 2,02 \\
\hline Nordeste & 1,02 & 26,63 & 18,89 & 54,48 & 1,19 \\
\hline $\begin{array}{l}\text { Médio Alto } \\
\text { Uruguai }\end{array}$ & 0,96 & 26,00 & 15,81 & 58,19 & 1,43 \\
\hline $\begin{array}{l}\text { Campos de } \\
\text { Cima da } \\
\text { Serra }\end{array}$ & 0,90 & 29,52 & 14,94 & 55,53 & 0,92 \\
\hline Jacuí Centro & 0,88 & 21,07 & 21,18 & 57,74 & 1,34 \\
\hline Hortênsias & 0,85 & 12,04 & 26,57 & 61,39 & 1,19 \\
\hline Celeiro & 0,83 & 28,75 & 13,18 & 58,07 & 1,32 \\
\hline Rio da Várzea & 0,81 & 27,73 & 15,86 & 56,42 & 1,08 \\
\hline $\begin{array}{l}\text { Vale do Jag- } \\
\text { uari }\end{array}$ & 0,63 & 27,57 & 11,21 & 61,22 & 1,10 \\
\hline $\begin{array}{l}\text { Alto da Serra } \\
\text { do Botucaraí }\end{array}$ & 0,59 & 28,48 & 10,12 & 61,41 & 0,97 \\
\hline $\begin{array}{l}\text { Rio Grande } \\
\text { do Sul }\end{array}$ & 100,00 & 8,69 & 29,21 & 62,10 & 100,00 \\
\hline
\end{tabular}

Fonte: Elaboração própria com base nos dados disponíveis em FEE/Centro de Informações Estatísticas/Núcleo de Contabilidade Social.

Recebido em: 16/05/2014. Acesso em: 25/03/2015. 